\title{
Metal-Complex Formation in Continuous-Flow Ligand-Exchange Reactors Studied by Electrospray Mass Spectrometry
}

\author{
J. G. Krabbe, A. R. de Boer, G. van der Zwan, H. Lingeman, \\ W. M. A. Niessen, and H. Irth \\ Faculty of Sciences, Department of Chemistry and Pharmaceutical Sciences, Section of Analytical Chemistry \\ and Applied Spectroscopy, Vrije Universiteit Amsterdam, Amsterdam, The Netherlands
}

\begin{abstract}
Electrospray ionization mass spectrometry was used to investigate complex formation of different metal complexes in a continuous-flow ligand-exchange reactor. A computer program was developed based on normal equilibrium calculations to predict the formation of various metal-ligand complexes. Corresponding to these calculations, infusion electrospray mass spectrometric experiments were performed to investigate the actual complex formation in solution. The data clearly show good correlation between the theoretically calculated formation of metal-ligand complexes and the experimental mass spectrometric data. Moreover, the approach demonstrates that the influence of the $\mathrm{pH}$ can be investigated using a similar approach. Indirectly, these infusion experiments provide information on relative binding constants of different ligands towards a metal-ion. To demonstrate this, a continuous-flow ligand-exchange detection system with mass spectrometric detection was developed. Injection of ligands, with different affinity for the metal-ion, into the reactor shows good correlation between binding constants and the response in the ligand-exchange detection system. Additional information on the introduced ligand, and the complexes formed after introduction of the ligand, can be obtained from interpretation of the mass spectra. (J Am Soc Mass Spectrom 2007, 18, 707-713) (C) 2007 American Society for Mass Spectrometry
\end{abstract}

$\mathrm{D}$ ue to the increasing interest in metal complexes and metal-ligand interactions in several fields, e.g., drug research [1,2] and catalyst design [3], novel detection methods are necessary. Conventional techniques to study these interactions and complexes are infrared spectroscopy, X-ray diffraction, and nuclear magnetic resonance spectroscopy (NMR) [4], but these techniques have several drawbacks. The use of electrospray ionization mass spectrometry (ESI-MS) for studying metal-ions, metal-ligand interactions and metal complexes is readily recognized [5]. Using MS as a detection technique offers the advantage of being, in general, more sensitive than NMR and X-ray diffraction and opens up the possibility to screen complex samples. Moreover, MS enables simultaneous monitoring the response of ligand-exchange reactions and additionally obtaining chemical information about the specific compound $[6,7]$.

Today, MS is often used in studying host-guest complexes [8-10], structural elucidation by collisioninduced dissociation (CID) MS [11, 12], and studying relative binding constants of ligands to metal-ions [13,

Published online January 18, 2007

Address reprint requests to Dr. J. Krabbe, Faculty of Sciences, Department of Chemistry and Pharmaceutical Sciences, Section of Analytical Chemistry and Applied Spectroscopy, Vrije Universiteit Amsterdam, De Boelelaan 1083, 1081 HV Amsterdam, The Netherlands. E-mail: jg.krabbe@few.vu.nl
14]. Additionally, due to the liquid-based ionization in the ESI process, it is suitable for studying liquid-phase reactions, e.g., ligand-exchange reactions [6, 7], which enables the study of complex systems.

In general, the assumption is made of a good correlation between complexes formed in solution and what is observed in the mass spectrum [15]. FAB-MS and ESI-MS have been used in the past to evaluate binding selectivities of various compounds, e.g., caged crown ethers to metal-ions [16]. An excellent correlation between obtained ESI mass spectral data and expected binding selectivities has been reported in several papers $[13,17,18]$, although several parameters should be kept in mind. For a good correlation between complex formation in solution and what is observed in the mass spectrum [14], particularly the competing effect of the solvent, the conditions and ionization efficiencies of the different complexes, and molecules have to be taken into account.

This report describes a fundamental approach in studying metal complexes with ESI-MS. A computer program was developed to calculate which complexes are formed under predefined conditions, based on the affinities of the relevant ligands to the metal-ion and the experimental conditions. As an example, the theory describes the influence of increasing total ligand concentrations $\mathrm{L}_{0}$ at different $\mathrm{pH}$ of the solution on the 
formation of different metal-ligand complexes. This theoretical approach is mimicked by monitoring the formation of the different complexes at increasing total ligand concentration with MS. Moreover, mass spectral data at different concentrations of ligand is evaluated to obtain a better insight about formed complexes at predefined conditions. The theory, as well as the mass spectral data, can aid in both the design of new ligandexchange reactions for analytical purposes [7] and in the interpretation of these interactions studied by MS, since they are involved in all kinds of processes, e.g., in biological [19] and industrial processes [3]. Additionally, the mass spectral data aid in the identification of specific compounds, e.g., catalytic species or intermediates, responsible for certain processes. This fundamental approach was extended by studying several ligandexchange reactions by MS. A continuous-flow ligandexchange detection method was used to selectively detect certain ligands, and to correlate the response of the detector to the relative affinities of certain ligands of interest to the metal-ions.

\section{Experimental}

\section{Materials}

Acetonitrile and methanol were purchased from Baker (Deventer, The Netherlands) and were purified over a $0.45 \mu \mathrm{m}$ Millipore filter (Bedford, MA). The nitrate salts of $\mathrm{Cu}(\mathrm{II})$ and $\mathrm{Zn}$ (II) and all ligands were purchased from Sigma-Aldrich (Steinheim, Germany), except for nicotinamide, 2-(aminomethyl)pyridine, and 4-picoline, which were purchased from Acros Organics (Geel, Belgium).

\section{Solution Preparation}

Stock solutions of $10 \mathrm{mM}$ ligands were prepared in methanol, except for 4,7-dimethyl-1,10-phenanthroline, which had a stock concentration of $4 \mathrm{mM}$. $\mathrm{Cu}$ (II) and $\mathrm{Zn}$ (II)-solutions were prepared in Milli-Q water (Bedford, MA). The reagent solution was prepared by adding a stock solution of metal-ion to a solution of ligand in ammonium formate-formic acid solution $(20 \mathrm{mM}$; $\mathrm{pH}$ 6.5) containing $50 \%$ methanol. The actual conditions and concentrations of the reagent solutions used are indicated either in the text or in the figure legends.

\section{Setup for Infusion Experiments}

The setup for the preliminary infusion experiments on the on-line mixing of solutions of metal salts and ligands is shown in Figure 1.

The system consisted of a Shimadzu (Hertogenbosch, The Netherlands) LCMS-2010A, and a separate Shimadzu LC-10Ai pump (Pump 2). The LCMS-2010A consisted of two LC-10ADvp pumps (pump 1a and pump 1b), a SCL-10ADvp system controller, a SIL10ADvp autosampler, a CTO-ACvp oven, and a single

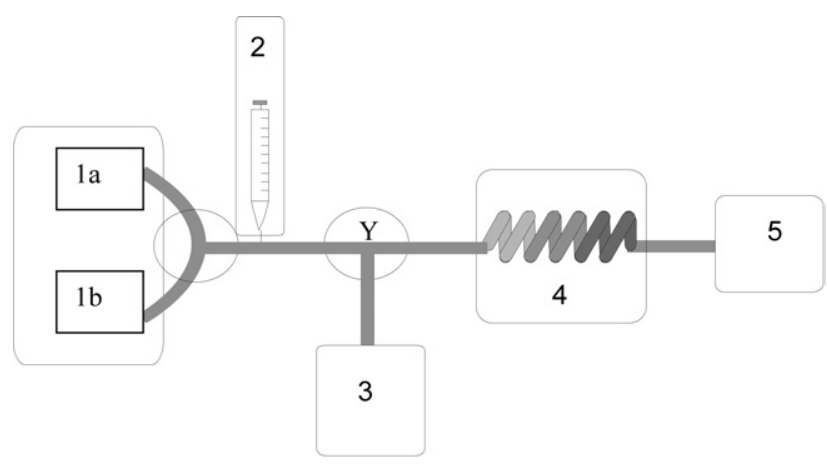

Figure 1. Schematic of the set-up used in infusion and directinjection experiments. For the direct-infusion experiments, pump $1 \mathrm{a}$ and pump $1 \mathrm{~b}$ generate a concentration gradient of either metal-ions or a ligand at a flow-rate of $50 \mu \mathrm{L} / \mathrm{min}$ (unless otherwise ${ }^{\circ}$ reported), ${ }^{\circ}$ the ${ }^{\circ}$ second ${ }^{\circ}$ pump $^{\circ}[3]^{\circ}$ continuously ${ }^{\circ}$ delivers the ligand or metal-ion of interest at $50 \mu \mathrm{L} / \mathrm{min}$ (unless otherwise reported), 4a $10 \mu \mathrm{L}$ thermostated reaction coil, and 5 the ESI-MS instrument. For the direct-injection experiments, additionally an

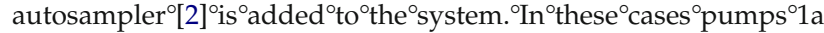
and $1 \mathrm{~b}$ generate a sample carrier-flo. ( $50 \mu \mathrm{L} / \mathrm{min}$ running buffer unless otherwise reported); and 2, the reagent pump provides 50 $\mu \mathrm{L} / \mathrm{min}$ metal-ion-reporter-ligand solution (unless otherwise reported)).

quadruple mass spectrometer equipped with an ESI probe. The binary pumps $1 \mathrm{a}$ and $1 \mathrm{~b}$ were used to generate a concentration gradient of either a metal-ion or a ligand at $50 \mu \mathrm{L} / \mathrm{min}$. Thus, pump 1a was pumping the running buffer consisting of methanol $/ 5 \mathrm{mM}$ ammonium formate $(50 / 50 \mathrm{vol} / \mathrm{vol})$ and pump $1 \mathrm{~b}$ was pumping a certain concentration of either metal-ions or ligand in running buffer. The LC-10Ai pump (pump 3) delivered, at $50 \mu \mathrm{L} / \mathrm{min}$, either the ligand or the metalion solution at a fixed concentration. The total flow into the home-made $40 \mu \mathrm{L}, 0.18 \mathrm{~mm}$ i.d. knitted PEEK reaction coil and the ESI-MS was $100 \mu \mathrm{L} / \mathrm{min}$. The reaction coil was thermostatted at $60^{\circ} \mathrm{C}$ by means of a water bath.

\section{Setup for Direct-Injection-Ligand-Exchange- ESI-MS}

The general set-up applied in experiments involving the direct-injection combination with the continuous-flow ligand-exchange reaction coupled to ESI-MS was very similar to the direct-infusion system. An autosampler was placed between the binary gradient pump 1 and the Y-piece for the mixing of the solution from pump 2 (see ${ }^{\circ}$ Figure $^{\circ} 1$ ).

In the continuous-flow detection system, the metal/ reporter-ligand solution $(50 \mu \mathrm{L} / \mathrm{min})$ was continuously mixed with a sample carrier flow (50 $\mu \mathrm{L} / \mathrm{min})$ into which the pure compounds were directly injected.

\section{Mass Spectrometry Settings}

MS detection was performed in positive-ion ESI. The probe voltage was $4 \mathrm{kV}$. Nitrogen $(99.999 \%$ purity, 
Praxair; Oevel, Belgium) gas flow was set at $1.5 \mathrm{~L} / \mathrm{min}$. A nitrogen counter gas flow was set at $0.06 \mathrm{MPA}$, which was applied to obtain better solvent evaporation. The curved desolvation line (CDL) temperature and the block temperature were set at $200^{\circ} \mathrm{C}$. ESI-MS data were acquired by switching between full-spectrum mode and selected-ion monitoring (SIM), detecting a number of specific $m / z$-values related to the reporter-ligand, the metal-reporter-ligand complex, the ligand of interest, and/or complexes of the metal-ion and the ligand of interest. In addition to the ligand and complex $\mathrm{m} / \mathrm{z}$ values, a system monitoring compound (SMC) was continuously detected in SIM during the direct injection to monitor the overall stability of the system and possible ion suppression effects.

\section{MS/MS Settings}

For structural elucidation and complex identification, a Micromass Q-TOF2 mass spectrometer (Wythenshawe, Manchester, UK) equipped with a Z-spray ESI source was used. The ESI source conditions were as follows: source temperature $80^{\circ} \mathrm{C}$, desolvation temperature $100^{\circ} \mathrm{C}$, capillary voltage $3 \mathrm{kV}$. The cone voltage was set at $30 \mathrm{~V}$. Nitrogen (99.999\% purity; Praxair) was used with flow rates of $20 \mathrm{~L} / \mathrm{h}$ for nebulization, $50 \mathrm{~L} / \mathrm{h}$ for cone gas, and $350 \mathrm{~L} / \mathrm{h}$ for desolvation. Argon (99.9995\% purity; Praxair) was used as collision gas in MS/MS experiments.

\section{Results and Discussion}

\section{General Setup}

The set-up used for both infusion experiments and flow-injection ${ }^{\circ}$ analysis ${ }^{\circ}$ is $^{\circ}$ shown $^{\circ}$ in ${ }^{\circ}$ Figure $^{\circ} 1 .^{\circ}$ Pump $^{\circ} 3$ continuously introduces a constant concentration of metal-ion. The binary gradient pump (pumps 1a and $1 b)$ delivers the ligand to be studied at the concentration range defined by the gradient settings. In typical experiments, the binary pump was set to run a 0 to $100 \%$ gradient of the ligand of interest in $20 \mathrm{mM}$ ammonium formate-formic acid buffer/methanol (50/50 vol/vol) at a total flow rate of $100 \mu \mathrm{L} / \mathrm{min}$. ESI-MS was used to monitor both the free ligand and metal-ligand complex concentrations in the full scan mode. For flow-injection experiments, an autoinjector was placed between pump 1 and the mixing union $Y$, using pump 1 as a sample carrier flow and pump 3 to deliver the premixed metal-reporter-ligand solution.

\section{Infusion Experiments (Zn(II) and 1,10-Phenanthroline)}

In many papers describing ESI-MS detection of metalligand complexes, the assumption is made that ESI mass spectra reflect, to a large extent, the composition of the ${ }^{\text {'metal }}{ }^{\circ} \mathrm{Complex}^{\text {'formed }}$ in solution $[9,10,15,18]$, although in-source fragmentation should be kept in
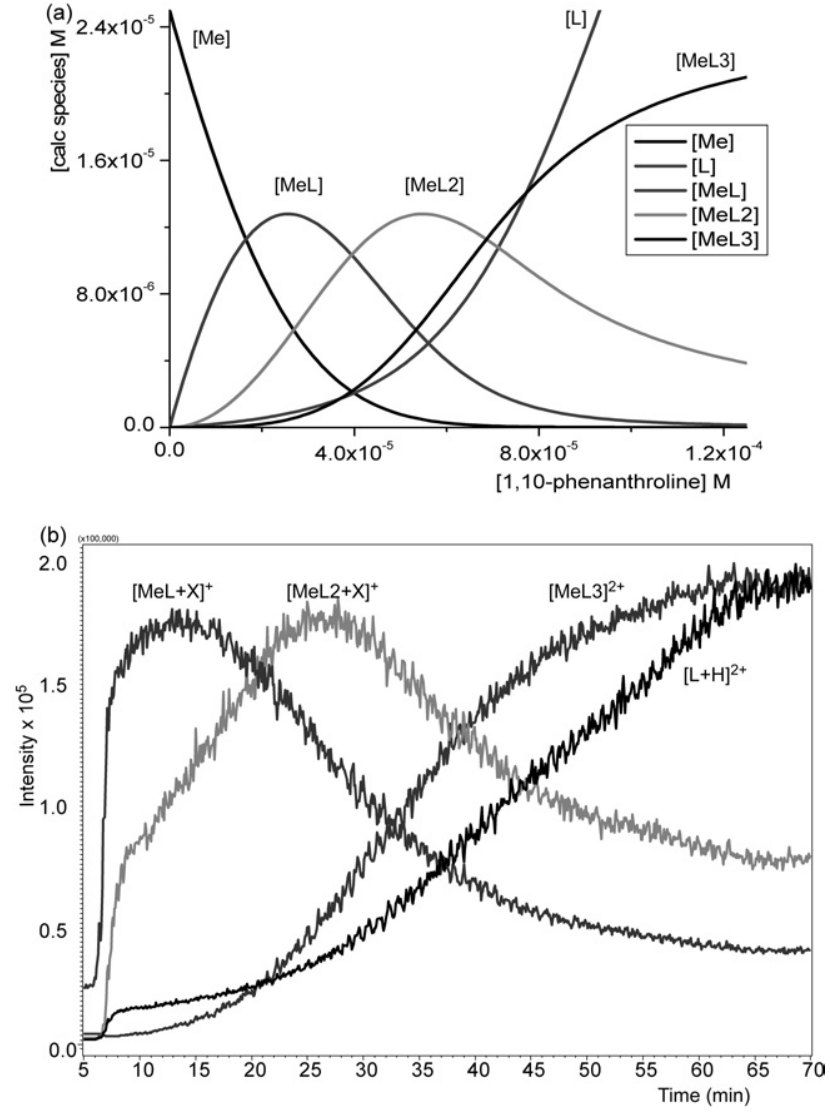

Figure 2. (a) Theoretical plot of the complex formation of $\mathrm{Zn}$ (II) with 1,10-phenanthroline at different concentrations of 1,10phenanthroline at a $\mathrm{pH}^{*}$ 6.5. (b) Obtained mass chromatogram for experimental approach at a $\mathrm{pH}^{*} 6.5$. A continuous flow of $50 \mu \mathrm{M}$ $\mathrm{Zn}$ (II) was mixed with a gradient of the concentration of 1,10phenanthroline in time. The gradient consisted of $0 \mu \mathrm{M}$ to $250 \mu \mathrm{M}$ in $60 \mathrm{~min}$. The maximum concentration of 1,10-phenanthroline was $250 \mu \mathrm{M}$. The total concentration of $\mathrm{Zn}$ (II) and 1,10-phenanthroline that reached the MS was $25 \mu \mathrm{M}$ and $125 \mu \mathrm{M}$, respectively.

mind $^{\circ}\left[20{ }^{\circ} 21\right] .^{\circ}$ To $^{\circ}$ evaluate $^{\circ}$ the ${ }^{\circ}$ correlation $^{\circ}$ between $^{\circ}$ solution complex formation and the observed mass spectrum, a computer program was developed to calculate the type and concentration of metal complexes formed under predefined conditions as a function of experimental parameters. Since the presence of methanol alters the $\mathrm{pH}$, the apparent $\mathrm{pH}^{*}$, reflecting the actual $\mathrm{pH}$ after the addition of methanol $\left(\mathrm{pH}^{*}\right.$ is measured with a $\mathrm{pH}$-meter), is used in the calculations of the different complexes throughout this paper.

Figure $2 a^{\circ}$ displays $^{\circ}$ the ${ }^{\circ}$ theoretical ${ }^{\circ}$ plot $^{\circ}$ of ${ }^{\circ}$ the ${ }^{\circ}$ concentration of the different metal complexes as a function of the concentrations of $\mathrm{Zn}(\mathrm{II})$, indicated as $\mathrm{Me}$, and 1,10phenanthroline $\left(\mathrm{C}_{12} \mathrm{H}_{8} \mathrm{~N}_{2}, 180.1 \mathrm{Da}\right)$, indicated as $\mathrm{L}$. The $\mathrm{Zn}$ (II) concentration of $25 \mu \mathrm{M}$ and the $\mathrm{pH}\left(\mathrm{pH}^{*} 6.5\right)$ are kept constant, while the ligand concentration is increased in time from 0 to $125 \mu \mathrm{M}$. $\mathrm{Zn}$ (II) can bind three bidentate ligands such as 1,10-phenanthroline, resulting in the formation of 1:1 (MeL), 1:2 $\left(\mathrm{MeL}_{2}\right)$, and 1:3 $\left(\mathrm{MeL}_{3}\right)$ metal-ligand complexes. From these calculations, the ligand concentrations can be derived, for which max- 


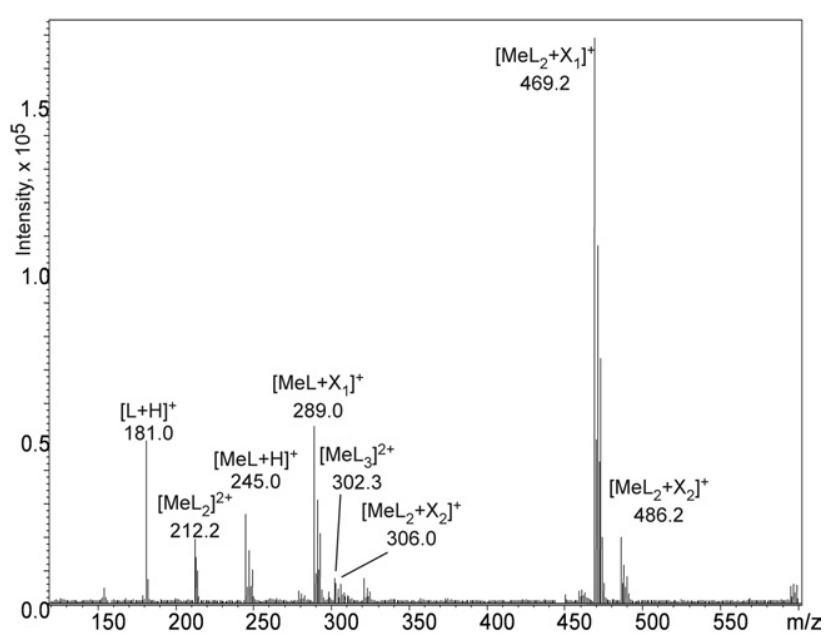

Figure 3. Average mass spectrum when the maximum concentration of 1:1 $\mathrm{Zn}: 1,10$-phenanthroline complex is formed $\left(\mathrm{pH}^{*} 6.5\right)$; where $\mathrm{M}=\mathrm{Zn}(\mathrm{II}) ; \mathrm{L}=1,10$-phenanthroline; $\mathrm{X}_{1}=$ formate and $\mathrm{X}_{2}$ $=$ nitrate.

ima of the individual metal-ligand complexes can be observed.

The $\mathrm{m} / z$ traces ${ }^{\circ}$ shown ${ }^{\circ}{ }^{\circ}{ }^{\circ}$ Figure ${ }^{\circ} 2 \mathrm{~b}$, ${ }^{\circ}$ reflect ${ }^{\circ}$ the ${ }^{\circ}$ experimentally measured responses for some of the observed metal-complex species during an infusion experiment. For clarification, the traces are normalized. Good correlation between the theoretical plot and the experimental data is achieved. Although a close relationship between the observed intensity of the mass spectrum and the calculated concentration of the formed complex was reported for 1:1 complexes of crown ethers with $\mathrm{Na}^{+}$ and ${ }^{\circ} \mathrm{K}^{+}{ }^{\circ}[18],{ }^{\circ}$ in $^{\circ}$ the ${ }^{\circ}$ present ${ }^{\circ}$ case $^{\circ}$ it $^{\circ}$ is $^{\circ}$ more $^{\circ}$ difficult ${ }^{\circ}$ to correlate intensities to concentrations of metal complexes because various complexes are formed (see below) and these complexes appear to have different ionization efficiencies. Despite this limitation, the measured optimum total ligand concentration for the maximum concentration of $\mathrm{MeL}(\approx 23 \mu \mathrm{M})$ and $\mathrm{MeL}_{2}(\approx 50$ $\mu \mathrm{M})$ are in good agreement with the values predicted from the theoretical plot, $25 \mu \mathrm{M}$ and $53 \mu \mathrm{M}$, respectively.

Since complexes of $\mathrm{Zn}(\mathrm{II})$ show specific isotope patterns $\left({ }^{64} \mathrm{Zn}:{ }^{66} \mathrm{Zn}:{ }^{67} \mathrm{Zn}:{ }^{68} \mathrm{Zn}\right.$; 49:28:4:19), they can easily be ${ }^{\circ}$ recognized ${ }^{\circ}{ }^{\circ}$ the ${ }^{\circ}$ mass $^{\circ}$ spectrum. ${ }^{\circ}$ Figure $3^{\circ}$ shows ${ }^{\circ}$ an averaged mass spectrum measured at $\mathrm{pH}^{*} 6.5$ at a ligand concentration of $\sim 23 \mu \mathrm{M}$, at which the concentration of MeL is at a maximum. The spectrum shows the protonated 1,10-phenanthroline at $\mathrm{m} / \mathrm{z} 181$, various ions related to $\mathrm{MeL}$ as well as ions related to $\mathrm{MeL}_{2}$ and $\mathrm{MeL}_{3}$. Interestingly, the abundances of the peaks at $\mathrm{m} / \mathrm{z}$ 289 and 469, corresponding to [MeL + formate $^{+}$and $\left[\mathrm{MeL}_{2}+\right.$ formate $^{+}$, respectively, differ from what is predicted by the theoretical model. Under the conditions chosen, the MeL related signal is predicted to be similar to the $\mathrm{MeL}_{2}$ signal, whereas in the experimental data the ratio of the MeL:MeL ${ }_{2}$ signals is 1:4. This indicates that $\mathrm{MeL}_{2}$ shows significantly higher ioniza- tion efficiency than MeL. Despite the differences in ionization efficiency, the normalized patterns observed for $\mathrm{MeL}$ and $\mathrm{MeL}_{2}$ closely coincide with those predicted by the theoretical model; moreover, all observed $\mathrm{MeL}_{\mathrm{x}}$ complexes show a similar pattern.

Next to $\left[\mathrm{MeL}+\right.$ formate $^{+}$, a number of other MeLrelated ions are observed, e.g., peaks at $m / z 245$ and 321. While the latter can be explained as a methanol adduct of $\left[\mathrm{MeL}+\right.$ formate $^{+}$, as frequently observed in spectra from this type of ESI source, the peak at $\mathrm{m} / \mathrm{z} 245$ is more difficult to explain. The isotope pattern reveals that one $\mathrm{Zn}$ metal-ion is present and that the molecular species is singly charged. When the intensity of the peak at $\mathrm{m} / \mathrm{z}$ is plotted against the total concentration of ligand, it resembles the profile of $\left[\mathrm{MeL}_{2}+\right.$ formate $^{+}$. In-source CID and MS-MS experiments, however, demonstrate that the ion with $\mathrm{m} / \mathrm{z} 245$ may be a fragment of the ion with $\mathrm{m} / z 289$, which could be formed by the loss of $\mathrm{CO}_{2}$ from the $[\mathrm{MeL}+\text { formate }]^{+}$. Further fragmentation of the ion with $\mathrm{m} / \mathrm{z} 245$ in MS-MS results in protonated 1,10-phenanthroline $(\mathrm{m} / \mathrm{z} 181)$, which in turn can be fragmented by two subsequent losses of $\mathrm{HCN}$, similarly to protonated 1,10-phenanthroline itself. The fragmentation of the ion at $m / z 289$ is not yet fully understood: the loss of $\mathrm{CO}_{2}$ implies that the singly-charged ion with $\mathrm{m} / \mathrm{z} 245$ would be a complex of Zn(II), 1,10-phenanthroline and a hydride anion, while further fragmentation to the ion with $\mathrm{m} / \mathrm{z} 181$ should involve the loss of neutral $\mathrm{Zn}$.

Similar to MeL, a number of different ion species are observed for $\mathrm{MeL}_{2}$, e.g., a doubly-charged $\left[\mathrm{MeL}_{2}\right]^{2+}$ complex with $\mathrm{m} / \mathrm{z} 212$ and a $\left[\mathrm{MeL}_{2}+\text { nitrate }\right]^{+}$complex with $\mathrm{m} / \mathrm{z}$ 486.0. The latter complex is known from the literature ${ }^{\circ}[22],{ }^{\circ}$ but $^{\circ}$ under ${ }^{\circ}$ the ${ }^{\circ}$ present $^{\circ}$ conditions $^{\circ}$ the formate concentration from the ammonium formate buffer $(5 \mathrm{mM})$ exceeds the nitrate concentration $(50$ $\mu \mathrm{M})$, resulting from the zinc nitrate used. The formation of doubly charged ions implies that possibly a number of neutral complexes, e.g., $\left[\mathrm{MeL}+\right.$ (formate) $\left.{ }_{2}\right]$ or $[\mathrm{MeL}$ + formate + nitrate], are formed as well. These are obviously not observed under positive-ion ESI conditions, but to some extent they may obscure the actual agreement between the experimental and the theoretical $^{\circ}$ plot $^{\circ}\left(\right.$ Figure $\left.^{\circ} 2\right)$.

A small peak attributable to $\left[\mathrm{MeL}_{3}\right]^{2+}$ is observed in Figure $3^{\circ}$ as $^{\circ}$ well. This ${ }^{\circ}$ peak ${ }^{\circ}$ becomes ${ }^{\circ}$ obviously ${ }^{\circ}$ far ${ }^{\circ}$ more abundant in spectra acquired at higher ligand concentrations (data not shown). No $\left[\mathrm{MeL}_{3}+\right.$ formate ${ }^{+}$ions were observed at $m / z 649$. This suggests that in the MeL and $\mathrm{MeL}_{2}$ complexes, formate acts as inner-sphere ligands and not as outer-sphere anionic ligands.

\section{$p H^{*}$ Variation}

To study the influence of the $\mathrm{pH}$ on metal-complex formation, similar continuous-flow experiments were performed at a $\mathrm{pH}^{*}$ below the $\mathrm{pKa}$ of the ligand. At $\mathrm{pH}^{*}$ of 3.4, the increased competition between the $\mathrm{H}^{+}$and $\mathrm{M}^{n+}$ results in a shift of the total concentration of ligand 
Table 1. Complexes of $\mathrm{Cu}(\mathrm{II})$ and 2,2'-bipyridyl formed at a 1:1 metal to ligand ratio

\begin{tabular}{lcl}
\hline $\mathrm{m} / \mathrm{z}$ & \% Relative abundance & \multicolumn{1}{c}{ Interpretation } \\
\hline \hline 187.6 & 9 & {$\left[\mathrm{MeL}_{2}\right]^{2+}$} \\
$219.0^{\mathrm{a}}$ & & {$[\mathrm{MeL}]^{+}$} \\
219.9 & 6 & {$[\mathrm{MeL}+\mathrm{H}]^{+}$} \\
$236.9^{\mathrm{a}}$ & 14 & {$\left[\mathrm{MeL}+\mathrm{H}_{2} \mathrm{O}\right]^{+}$} \\
$251.0^{\mathrm{a}}$ & 15 & {$[\mathrm{MeL}+\mathrm{MeOH}]^{+}$} \\
264.0 & 100 & {$[\mathrm{MeL}+\text { formate }]^{+}$} \\
280.9 & 6 & {$\left[\mathrm{MeL}+\right.$ nitrate $^{+}$} \\
$375.1^{\text {a }}$ & 70 & {$\left[\mathrm{MeL}_{2}\right]^{+}$} \\
420.1 & 45 & {$\left[\mathrm{MeL}_{2}+\text { formate }\right]^{+}$} \\
437.2 & 5 & {$\left[\mathrm{MeL}_{2}^{+}+\right.$nitrate $^{+}$} \\
\hline
\end{tabular}

Indicates complexes of $\mathrm{Cu}(\mathrm{I})$.

at which the maximum concentration of the relevant complex is observed. Again, there is good agreement between the experimental plot at a $\mathrm{pH}^{*}$ of 3.4 and the theoretical plot (data not shown).

The averaged mass spectrum at the total ligand concentration for a maximum MeL complex at a $\mathrm{pH}^{*}$ of $3.4^{\circ}$ is $^{\circ}$ similar $^{\circ}$ to $^{\circ}$ Figure $^{\circ} 3,{ }^{\circ}$ excep $^{\circ}$ for $^{\circ}$ some $^{\circ}$ changes $^{\circ}$ in relative abundances of various ions, e.g., the $\left[\mathrm{MeL}_{2}\right]^{2+}$ $(m / z 212)$ is more abundant than $\left[\mathrm{MeL}_{2}+\text { formate }\right]^{+}$ $(m / z 469)$.

\section{Infusion Experiments (Cu(II) and 2,2'-Bipyridyl)}

Similar infusion experiments and correlation with theoretical plots were carried out for other combinations of a metal-ion and a bidentate ligand. The results obtained with $\mathrm{Cu}(\mathrm{II})$ and 2,2'-bipyridyl $\left(\mathrm{C}_{10} \mathrm{H}_{8} \mathrm{~N}_{2}, 156.1 \mathrm{Da}\right)$ are briefly discussed here, especially with respect to the mass $^{\circ}$ spectral $^{\circ}$ interpretation ${ }^{\circ}\left(\right.$ see $^{\circ}$ Table $\left.^{\circ} 1\right) .{ }^{\circ}$ Good $^{\circ}$ corre- $^{-}$ lation between the theoretical plot and the experimental results at various $\mathrm{pH}^{*}$ was achieved (data not shown). Table 1 shows the most ${ }^{\circ}$ abundant ${ }^{\circ}$ ions ${ }^{\circ}$ of averaged mass spectra observed at $\sim 45 \mu \mathrm{M} 2,2^{\prime}$-bipyridyl ( $\mathrm{pH}^{*} 6.5$ ), that is the ligand concentration where the MeL complex concentration is at a maximum.

Reduction of $\mathrm{Cu}(\mathrm{II})$ to $\mathrm{Cu}(\mathrm{I})$ can occur upon dissociation of its complex with certain ligands such as bipyri$\mathrm{dyl}^{\circ}[23]^{\circ}$ or $^{\circ}$ upon ${ }^{\circ}$ reduction ${ }^{\circ}$ of ${ }^{\circ} \mathrm{Cu}(\mathrm{II})^{\circ}$ complexes $^{\circ}$ in ${ }^{\circ}$ the reaction ${ }^{\circ}$ with $^{\circ}$ solvents, ${ }^{\circ}$ e.g., ${ }^{\circ}$ acetonitrile ${ }^{\circ}\left[24,{ }^{\circ} 25\right] .{ }^{\circ}{ }^{\circ}{ }^{\circ}$ the ESI process, the reduction of $\mathrm{Cu}(\mathrm{II})$ to $\mathrm{Cu}(\mathrm{I})$ is much faster than the process in solution. $\mathrm{Cu}(\mathrm{I})$ is a closed-shell ion $^{\circ}[4],{ }^{\circ}$ which $^{\circ}$ may $^{\circ}$ explain $^{\circ}$ the $^{\circ}$ ease $^{\circ}$ of $^{\circ}$ this $^{\circ}$ reaction. Keeping this in mind, several of the observed ions, e.g., $m / z 263.9,251.0$, and 375.0 are explained as [MeL + $\left.\mathrm{H}_{2} \mathrm{O}\right]^{+}$and $\left[\mathrm{MeL}+\mathrm{CH}_{3} \mathrm{OH}\right]^{+}$after reduction of $\mathrm{Cu}(\mathrm{II})$ to $\mathrm{Cu}(\mathrm{I})$. Again, a similar 1:1 complex $(\mathrm{m} / \mathrm{z} 219.9)$ as in the experiments with $\mathrm{Zn}(\mathrm{II})$ and 1,10-phenanthroline $\left(m / z\right.$ 245.0) was observed. $\mathrm{MeL}_{2}$ complexes show similar behavior where, next to $\left[\mathrm{MeL}_{2}+\text { formate }\right]^{+},\left[\mathrm{MeL}_{2}+\right.$ nitrate $]^{+}$, and $\left[\mathrm{MeL}_{2}\right]^{2+}$, the most abundant complex is $m / z$ 375, which can be interpreted as $\left[\mathrm{MeL}_{2}\right]^{+}$after reduction of $\mathrm{Cu}(\mathrm{II})$ to $\mathrm{Cu}(\mathrm{I})$. The $\mathrm{MeL}_{3}$ complexes expected are $\left[\mathrm{MeL}_{3}\right]^{+}$with $m / z 531$ with $\mathrm{Cu}(\mathrm{I}$ ) (not observed) or $\left[\mathrm{MeL}_{3}\right]^{2+}$ with $m / z 265.7$ with $\mathrm{Cu}(\mathrm{II})$.

\section{Direct-Injection Ligand-Exchange Detection}

Next to the characterization of different metal-ligand species, the ability to readily detect metal-ligand complexes by ESI-MS also offers the possibility to study ligand-exchange ${ }^{\circ}$ reactions. ${ }^{\circ} \mathrm{We}^{\circ}$ have ${ }^{\circ}$ demonstrated ${ }^{\circ}$ that ligand-exchange reactions can successfully be used as analytical ${ }^{\circ}$ tool $^{\circ}[6,7]$.

The principle of the ligand-exchange detection method relies on the exchange of a reporter-ligand with a competing ligand of interest. The extent of the exchange reaction depends on the concentration and the affinity of the ligand $\mathrm{L}$ for the metal-ion relative to the reporter-ligand $\mathrm{R}$. Indirectly, such infusion experiments can provide information on relative binding constants of ligands towards a metal-ion. Since the concentration of $\mathrm{R}$ is continuously monitored by ESI-MS, a positive response in the MS-trace can be related a ligand with a high affinity (relative to the reporter-ligand). By changing the nature of $\mathrm{R}$, and therefore the binding strength of $\mathrm{MeR}$, the method can be tuned to achieve either higher ${ }^{\circ}$ or $^{\circ}$ lower ${ }^{\circ}$ selectivity ${ }^{\circ}[7] .{ }^{\circ}$ Furthermore, ${ }^{\circ}$ using ${ }^{\circ} \mathrm{MS}$ as detection method, both $\mathrm{R}$ and MeR can be monitored to measure the extent of the ligand-exchange reaction. Typically, the species with the highest ionization efficiency are finally selected as reporter molecule.

Next to the ionization efficiency, the binding constant of MeR and the number of available binding sites have to be considered. Weak MeR complexes result in an easy dissociation of the complex and, therefore, a decrease of the MeR signal. Moreover, when all available coordination sites are occupied, a decrease of the reporter complex relies only on the exchange itself. Figure $4^{\circ}$ displays the ligand-exchange ${ }^{\circ}$ detection 9 method for different concentrations of ligands with a known affinity for $\mathrm{Cu}(\mathrm{II})$ using 2,2'-bipyridyl as reporter-ligand $\mathrm{R}$. The upper trace corresponds to the protonated molecule of the free 2,2'-bipyridyl. A peak in the $2,2^{\prime}$-bipyridyl trace indicates that ligand exchange has occurred upon injection of a ligand of interest. Additional proof that ligand exchange occurred is obtained by analyzing the MS trace corresponding to one or more copper-2,2'-bipyridyl complex species. In the present example, $m / z$ 264.0, corresponding to $[\mathrm{MeR}+$ formate $]^{+}$, was used and a ligand-exchange reaction results in a negative peak. The ESI-MS spectrum provides additional information on identity of the analyte ligand and the metal-analyte complexes formed. This is especially interesting when dealing with unknown ligands or when information about specific metal complexes is required.

The response in the free 2,2'-bipyridyl trace is related to the relative binding constants of the $\mathrm{Cu}(\mathrm{II})$-analyte complexes. EDTA, which forms strong complexes with $\mathrm{Cu}(\mathrm{II})$, shows the highest response. Increasing EDTA concentrations result in increasing positive peak heights in the free $2,2^{\prime}$-bipyridyl trace and increasing negative peak heights in the $\mathrm{Cu}(\mathrm{II})-2,2^{\prime}$-bipyridyl trace. The molecular structure of the injected ligand also influ- 


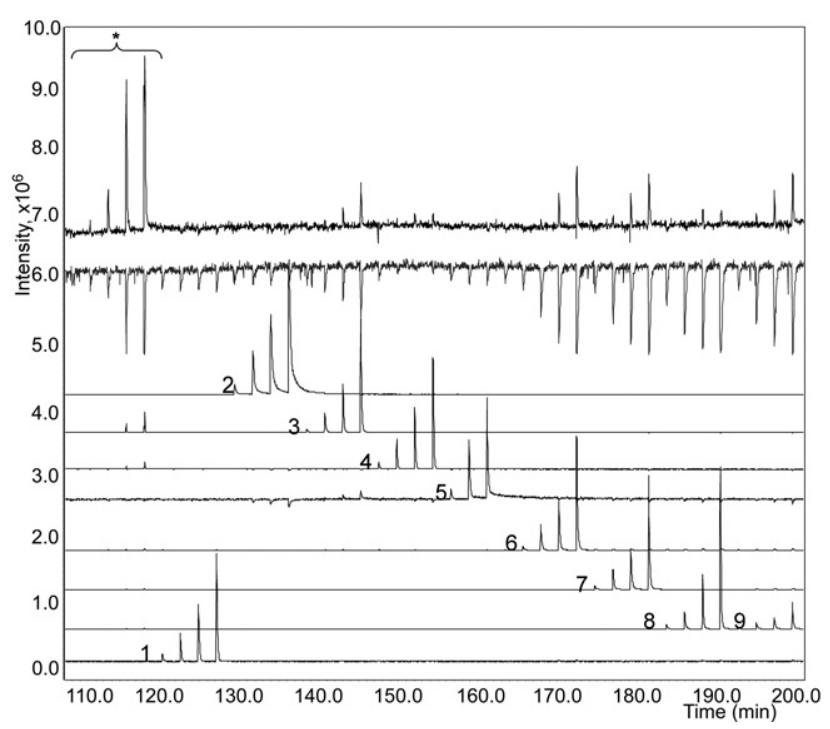

Figure 4. Ligand-exchange detection of different ligands. Reagent conditions: $\mathrm{Cu}$ (II)-(2,2'-bipyridyl $)_{2}$ in $5 \mathrm{mM} \mathrm{NH}_{4} \mathrm{HCO}_{2}$ / methanol $(50 / 50 \mathrm{vol} / \mathrm{vol}) \mathrm{pH}^{*} 6.5$. The reporter-ligand trace $(\mathrm{R})$ is 2,2'-bipyridyl $\left([\mathrm{M}+\mathrm{H}]^{+} ; m / z\right.$ 157) and the complex related trace

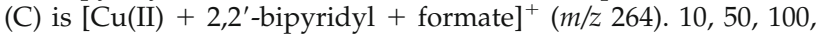
and $200 \mu \mathrm{M}$ injections $(10 \mu \mathrm{L})$ are performed of the ligands of interest. 1, glycinamide $(\mathrm{m} / \mathrm{z} 75) ; 2$, 2-aminomethyl-pyridine $(\mathrm{m} / \mathrm{z}$ 109); 4, benzimidazole $(\mathrm{m} / \mathrm{z} 119) ; 5$, nicotinamide $(\mathrm{m} / \mathrm{z} 123) ; 6$, 1,10-phenanthroline $(\mathrm{m} / \mathrm{z} 181) ; 7$, 5-methyl-1,10-phenanthroline $(\mathrm{m} / \mathrm{z}$ 195); 8, 2,9-dimethyl-1,10-phenanthroline $(\mathrm{m} / \mathrm{z} 209) ; 9$ 4,7dimethyl-1,10-phenanthroline $(\mathrm{m} / \mathrm{z} 209) .{ }^{*} 10,50,100$, and $200 \mu \mathrm{M}$ injections $(10 \mu \mathrm{L})$ of EDTA, which is not observed as a ligand in positive electrospray mass spectrometry, since it has an overall negative charge.

ences the response of the ligand-exchange detection. EDTA is a hexadentate ligand, which, in principle, can displace or exchange three bidentate reporter-ligands from MeR, whereas upon injection of a bidentate ligand, e.g., 1,10-phenanthroline, only one reporter-ligand is exchanged. This effect is substantiated by the results $^{\circ}\left(\text { Figure }^{\circ} 4\right)^{\circ}$ where ${ }^{\circ}$ EDTA $^{\circ}$ gives $^{\circ} a^{\circ}$ higher ${ }^{\circ}$ response in the reporter-ligand trace than 1,10-phenanthroline. At the same time, the decrease in the metal-reporterligand complex trace is similar for the injection of EDTA or 1,10-phenanthroline. One molecule of EDTA exchanges three reporter-ligand molecules from one metal-reporter-ligand complex molecule, but affects only one metal-reporter-ligand complex, whereas a 1,10phenanthroline molecule only exchanges one reporterligand molecule from that complex.

In some applications, it may be of interest to study the complexes formed with the analyte ligands in detail. Next to homogeneous complexes, the formation of heterogeneous, mixed-ligand complexes has to be considered. By injecting 5-methyl-1,10-phenanthroline $\left(\mathrm{C}_{13} \mathrm{H}_{10} \mathrm{~N}_{2}, 194.1 \mathrm{Da}\right)$ in the $\mathrm{Cu}(\mathrm{II})-2,2^{\prime}$-bipyridyl ligandexchange detection system, all three types of metal complexes may be formed, i.e., complexes of the analyte ligand $(\mathrm{MeL})$, mixed complexes with both the analyte ligand and reporter-ligand (MeLR), and complexes with the reporter-ligand (MeR) (data not shown).

\section{Correlation of Response in Ligand-Exchange Detection and Affinity of the Injected Ligands}

As expected, an increase in the concentration of the injected ligand results in an increase in the response in the reporter-ligand trace. For EDTA, 1,10-phenanthroline, 5-methyl-1,10-phenanthroline, and 4,7-dimethyl1,10-phenanthroline, the increase of the response shows a linear relationship with the increase in concentration (correlation coefficient of $>0.99$ ), while such a linear correlation is not observed for 2,9-dimethyl-1,10phenanthroline. The latter may be caused by steric hindrance (which is also related to the equilibration constant) and/or ion suppression.

As expected, the type of MeL complex formed depends on the concentration of the ligand of interest. At low concentrations, the MeL complex species are relatively more abundant, while at higher injected concentrations a shift to the $\mathrm{MeL}_{2}$ and $\mathrm{MeL}_{3}$ complexes is observed. At the same time, data show that the response due to $\mathrm{MeL}_{3}$ complexes starts decreasing at lower ligand concentration, while the decrease of $\mathrm{MeL}_{2}$ and MeL starts at higher ligand concentrations.

\section{Conclusions}

Continuous-flow ligand-exchange detection systems coupled to ESI-MS are useful tools in studying interactions between metal-ions and a variety of ligands. In principle, monitoring the dissociation and formation of metal-ligand complexes by means of ESI-MS provides a wealth of information. However, a proper picture on the liquid-phase complexation processes can only be obtained if the mass spectral data adequately reflect the metal-ligand complexes formed in solution. This study demonstrates that for several model systems good correlation is found between experimental data obtained by ESI-MS and theoretically predicted metalligand concentrations, even when experimental parameters like solution $\mathrm{pH}$ vary. Infusion experiments were also found to be a fast method to obtain a proper insight in the complexes formed before the development of an actual ligand-exchange detection system. The various complexes formed may well differ in ionization efficiency. In addition, these experiments show the complexity of the liquid phase constituents during complex formation and ligand-exchange reactions.

Injection of several ligands with different affinity for the metal-ion in a continuous-flow ligand-exchange reaction clearly shows that there is a good correlation between binding constants and the ligand-exchange detection response. Additional information of the introduced ligand and the complexes formed after introduction of the ligand can be obtained from interpretation of the mass spectrum.

This fundamental approach may aid in the future design of a customized ligand-exchange reaction, e.g., as a selective detection method, to study relative binding constants or to study the ligand-metal interactions 
in general. The applicability of these ligand-exchange reactions is not restricted to the metal-ions $\mathrm{Cu}(\mathrm{II})$ and $\mathrm{Zn}(\mathrm{II})$, but can be expanded to other metal-ions of interest or ligands of interest.

\section{Acknowledgments}

The authors acknowledge Shimadzu Benelux for the loan of equipment.

\section{References}

1. Farrell, N. Biomedical Uses and Applications of Inorganic Chemistry. An Overview. Coord. Chem. Rev. 2002, 232, 1-4.

2. Molenveld, P.; Engbersen, J. F. J.; Kooijman, H.; Spek, A. L.; Reinhoudt D. N. Efficient Catalytic Phosphate Diester Cleavage by the Synergetic Action of Two $\mathrm{Cu}(\mathrm{II})$ Centers in a Dinuclear Cis-Diaqua Cu(II) Calix[4]Arene Enzyme Model. J. Am. Chem. Soc. 1998, 120, 6726-6737.

3. Chen, P. Electrospray Ionization Tandem Mass Spectrometry in HighThroughput Screening of Homogeneous Catalysts. Angew. Chem. Int. Ed. 2003, 42, 2832-2847.

4. Chaparro, A. L.; Vachet, R. W. Tandem Mass Spectrometry of Cu(II) Complexes: The Effects of Ligand Donor Group on Dissociation. J. Mass Spectrom. 2003, 38, 333-342.

5. Traeger, J. C. Electrospray Mass Spectrometry of Organometallic Compounds. Int. J. Mass Spectrom. 2000, 200, 387-401.

6. Krabbe, J. G.; Lingeman, H.; Niessen, W. M. A.; Irth, H. LigandExchange Detection of Phosphorylated Peptides Using Liquid Chromatography Electrospray Mass Spectrometry. Anal. Chem. 2003, 75, 68536860 .

7. Krabbe, J. G.; Lingeman, H.; Niessen, W. M. A.; Irth, H. Screening for Metal Ligands by Liquid Chromatography-Ligand-Exchange-Electrospray Mass Spectrometry. J. Chromatogr. A 2005, 1093, 36-46.

8. Satterfield, M.; Brodbelt, J. S. Relative Binding Energies of Gas-Phase Pyridyl Ligand/Metal-Complexes by Energy-Variable Collisionally Activated Dissociation in a Quadrupole Ion Trap. Inorg. Chem. 2001, 40, 5393-5400.

9. Tsierkezos, N. G.; Schroder, D.; Schwarz, H. Complexation of Nickel(II) by Ethylenediamine Investigated by Means of Electrospray Ionization Mass Spectrometry. Int. J. Mass Spectrom. 2004, 235, 33-42.

10. Vincenti, M. Host-Guest Chemistry in the Mass Spectrometer. J. Mass Spectrom. 1995, 30, 925-939.

11. Jellen, E. E.; Chappell, A. M.; Ryzhov, V. Effects of Size of Noncovalent Complexes on Their Stability During Collision-Induced Dissociation. Rapid Commun. Mass Spectrom. 2002, 16, 1799-1804.
12. Kumar, M. R.; Prabhakar, S.; Kumar, M. K.; Reddy, T. J.; Vairamani, M. Dissociation of Gas-Phase Dimeric Complexes of Lactic Acid and Transition Metal-Ions Formed Under Electrospray Ionization Conditions; The Role of Reduction of the Metal-Ion. Rapid Commun. Mass Spectrom. 2005, 19, 113-120.

13. Blair, S. M.; Brodbelt, J. S.; Marchand, A. P.; Kumar, K. A.; Chong, H. S Evaluation of Binding Selectivities of Caged Crown Ligands Toward Heavy Metals by Electrospray Ionization/Quadrupole Ion Trap Mass Spectrometry. Anal. Chem. 2000, 72, 2433-2445.

14. Young, D. S.; Hung, H. Y.; Liu, L. K. An Easy and Rapid Method for Determination of Stability Constants by Electrospray Ionization Mass Spectrometry. Rapid Commun. Mass Spectrom. 1997, 11, 769-773.

15. Di Marco, V. B.; Bombi, G. G. Electrospray Mass Spectrometry (ESI-MS) in the Study of Metal-Ligand Solution Equilibria. Mass Spectrom. Rev. 2006, 25, 347-379.

16. Young, D. S.; Hung, H. Y.; Liu, L. K. Estimation of Selectivities and Relative Cationization Efficiencies of Different [Crown plus M] $(+)$ by Electrospray Mass Spectrometry. J. Mass Spectrom. 1997, 32, 432-437.

17. Goolsby, B. J.; Brodbelt, J. S.; Adou, E.; Blanda, M. Determination of Alkali Metal-Ion Binding Selectivities of Calixarenes by Matrix-Assisted Laser Desorption Ionization and Electrospray Ionization in a Quadrupole Ion Trap. Int. J. Mass Spectrom. 1999, 193, 197-204.

18. Wang, K. S.; Gokel, G. W. Correlation of Solution and Gas Phase Complexation Assessed by Electrospray Ionization Mass Spectrometry: Application to One-, Two-, and Three-ring Macrocycles. J. Org. Chem. 1996, 61, 4693-4697.

19. Gomez-Ariza, J. L.; Garcia-Barrera, T.; Lorenzo, F.; Bernal, V.; Villegas, M. J.; Oliveira, V. Use of Mass Spectrometry Techniques for the Characterization of Metal Bound to Proteins (Metallomics) in Biological Systems. Anal. Chim. Acta 2004, 524 15-22.

20. Press, W. H.; Flannery, B. P.; Teulkolsky, S. A.; Vetterling, W. T. Numerical Recipes in Pascal, 2nd ed.; Cambridge University Press: Cambridge, 1992; p 285.

21. Bure, C.; Lange, C. Comparison of Dissociation of Ions in an Electrospray Source, or a Collision Cell in Tandem Mass Spectrometry. Curr Org. Chem. 2003, 7, 1613-1624.

22. Kubwabo, C.; Vais, N.; Benoit, F. M. Characterization of Microcystins Using In-Source Collision-Induced Dissociation. Rapid Commun. Mass Spectrom. 2005, 19, 597-604.

23. Vachet, R. W.; Callahan, J. H. Quadrupole Ion Trap Studies of the Structure and Reactivity of Transition Metal-Ion Pair Complexes. J. Mass Spectrom. 2000, 35, 311-320.

24. Shen, J.; Brodbelt, J. Formation of Doubly Charged Transition MetalPolyether-Pyridyl Mixed-Ligand Complexes by Electrospray Ionization. J. Mass Spectrom. 1999, 34, 137-146.

25. Shvartsburg, A. A.; Wilkes, J. G.; Lay, J. O.; Siu, K. W. M. Fragmentation and Charge Transfer in Gas-Phase Complexes of Divalent Metal-Ions with Acetonitrile. Chem. Phys. Lett. 2001, 350, 216-224.

26. Seto, C.; Stone, J. A. The Reactions of $\mathrm{Cu} 2+(\mathrm{CH} 3 \mathrm{CN})(\mathrm{n})(\mathrm{n}=2-4)$ and $\mathrm{Cu} 2+(\mathrm{CH} 3 \mathrm{CN})(3)(\mathrm{H} 2 \mathrm{O})$ at low collision energy with neutral molecules in a triple sector quadrupole instrument. Int. J. Mass Spectrom. 1998, 175, 263-276. 